\title{
Testing the quality of underground transport in Bucharest
}

\author{
Alexandru STATESCU \\ The Bucharest University of Economic Studies, Bucharest, Romania \\ alexandrustatescu@yahoo.com
}

\begin{abstract}
In a city with overcrowded traffic, a component of the common transport is Bucharest transportation of metro (subway passenger transport on the railway network underground and surface) and is the core activity of METROREX S.A. The company aims each year a greater number of passengers according to the charts of the movement of subway trains to ensure adequate transport capacity as required and optimal conditions of comfort and safety. Each year, the company aims to find out the opinion of passengers on the transport conditions and, in this respect, organize a survey with the aim of testing the quality of underground transport in Bucharest in 16 subway stations considered to be representative. In this paper I intend to do an analysis using statistical research methods, of the quality of underground transport in Bucharest, using data from the survey conducted in the year 2014. Data collection in the stations was realized through 32 operators, by 2 in each station (one in each direction of travel) by completing questionnaires (using interview technique or face to face technique), using a sample considered representative of 2,400 travelers with a margin of error of $\pm 2 \%$ on a $95 \%$ probability level. Data collection was made during the period when passenger traffic is large enough to provide a good representation of data and cover the entire program running underground. The questionnaire contains eight questions that have allowed those who responded to the survey to fit in the time between trains in circulation. In 2016, the structure of the questionnaire was modified, questions were modified for a more effective assessment of characteristics of observation. The answers to the questions contained in the questionnaire were collected by operators in the 16 subway stations: Piața Unirii 1 and 2, Piața Victoriei 1 and 2, Dristor 2, Nicolae Grigorescu, Universitate, Piața Sudului, Pipera, Eroilor, Gara de Nord 1, Obor, Crângași, Pantelimon, Parc Bazilescu and 1 December 1918, analyzed and processed based on 2400 questionnaires. A new category of polls states in the present and is determined by evolutions in computer networks and communication, are called online surveys conducted on the Web. Also in this paper, I propose the implementation of a solution based on an online survey website that includes the online version of the questionnaire used to collect data from the virtual environment.
\end{abstract}

Keywords: survey, questionnaire, qualitative variables, regression model, hypotheses, multifactorial regression.

\section{Introduction}

Public transportation services represent the activities authorized by the administration to meet the traveling needs of citizens, commuters, traders and other categories of people, sometimes with tusristic, sports and leisure purposes, and it has the following features:

- satisfy a social need;

- it is in permanent legal relationship with the administrative system that was established and which manages it;

- provide goods and / or services that meet the interests of a group or society in general;

- it is subject to a legal regime governed by public law principles;

- meet general social interests for which it was established;

- it is created or is canceled following a decision by the administrative management;

- is done through public establishments; 
Consumption of public services is an important indicator of quality of life in a country. For example, the organization of public health services, education, transport, safety, security and sanitation provides information on the living standards of consumers of the existence of concerns for environmental conservation. Quality of public services is given by the degree to which they meet the needs of permanent PICBE | 1089 interest of consumers, which may be expressed by time spent on services, the degree of comfort provided by such services, or by the effect they have on intellect, health, consumer safety and integrity.

Subway offers the largest carrying capacity of urban transport, with a potential 5 times bigger than any surface transport system; speeder can develop other means of transportation, reaching safe transport, regular and comfortable.

In the literature there are many techniques for measuring service quality and customer satisfaction, for public transport as in other service industries. These techniques are based on customer evaluation. The evaluation of service quality and customer satisfaction can be obtained according to different methods: by asking customers the perception/satisfaction on service quality, by asking the expectation/importance, or by asking both perception and expectation.

The techniques for measuring service quality and customer satisfaction can be identified in two different categories. The first one includes methods of statistical analysis, such as quadrant and gap analysis, factor analysis, scattergrams, bivariate correlation, cluster analysis, and conjoint analysis. Some of these provide an evaluation of the individual service attributes, others provide the relationship of attributes with overall satisfaction. The second category of techniques consists in estimation of the coefficients by modelling. The models relate global service quality (dependent variable) to some attributes (independent variables). There are linear models, like multiple regression models, and non-linear models, like the structural equation model (SEM) and Logit models in which all random components are independently and identically distributed according to a Gumbel random variable.

In this paper the purpose is measuring service quality and customer satisfaction(dependent variable) of the underground public transportation service using an opinion poll, and based on the answers for each question, to build an econometric model in order to establish how each attribute(independent variable) quantified as an answer influences the overall satisfaction.

\section{The opinion poll. The questionnaire and survey \\ Definitions}

The survey is a method of knowledge of public opinion based on the questionnaire and sampling. The term poll is equivalent to Public Opinion Polls (English) and one of Demoskopie (German) (Zamfir and Vlăsceanu, 1993). The term of survey research is a partial research whose purpose is that based on results from a taken rigorous sample to estimate total population parameters based on the principles of probability theory, mathematical statistics and the law of large numbers (Porojan, 2006).

Public opinion poll aims knowledge of complex preferences expressed by a significant number of people, on an issue of general importance.

This type of sociological research has as the differential note the restriction area of knowledge to the public and is based on interrogative methods for gathering information and sampling techniques (Isaic-Maniu et al., 1999). 
Public opinion is a complex of preferences expressed by a significant number of people on an issue of general importance. It represents a collection of ideas and judgments that have certain stability, momentary reactions are not simple, but not necessarily based on a scientific basis (Novak, 1996).

The survey is a kind of sociological inquiry with the following characteristics:

- Opinion focuses on appearance, subjective social reality;

- Focuses on issues that raise a substantial public interest;

- Is achieved in a very short time with simple and clearly structured questionnaires and samples to ensure reasonable representation of general assessments pursued;

- The results are presented in a simple form, without resorting to sophisticated means of processing and interpretation of information;

- It is highly descriptive (Rotariu and Iluţ, 2006).

The aim of any survey is to estimate population parameters based on results from the sample. There are two phases:

a) description of static phase which consists in collecting and processing information regarding the sample, ie obtaining statistics based on sample;

b) inference static phase consisting of exinderea results based on the sample, estimating such parameters entire population.

Subject to an opinion poll it is a matter of public interest. A general issue assumes two conditions:

- Present a social significance, ie relevant to the population that constitutes the research community;

- Be it a controversial issue.

Of all the phenomena of reality and admit that stir social interest with multiple meanings interpretations can be objects of the opinion poll only those that are accessible knowledge and understanding by the population investigated. In this respect the necessary two observations:

a) The non answers given in a public opinion poll are related to the degree of proximity in relation to the subjects under investigation.

b) One of the most damaging effects of the survey is to put subjects in a situation to answer questions that they have not put or do not understand (Isaic-Maniu et al., 1999).

As a statistical technique, the survey is based on this principle: quantitative opinions are equal and as such measurable static treatment.

The methodological approach of the research sample assumes the completion of milestones and solving various problems.

a) Goal setting

Mainly, a survey can pursue two main objectives:

- estimation of population parameters (mean, proportions, etc.)

- checking assumptions about the connections between phenomena.

The goal setting depend on all subsequent steps: the population studied, techniques used, method of sampling etc.Determine the objective is to determine what is feasible with the available materials (time, money, number of operators).

b) Determination of the universe of the investigation

Refers to the population from which the sample will be extracted and on which will extend the survey results.

c) Choice of techniques

Transmission of information from subject to operator can be done either orally or in writing. 
d) Develop hypotheses

The hypothesis of a causal relationship is the statement in a form which permits empirical verification. To have the quality of hypothesis must be testable proposition, that by confronting reality, be confirmed or refuted.

e) Elaboration of the questionnaire

The questionnaire form that materializes survey program and therefore its PICBE | 1091 quality (clarity, length, difficulty) depends heavily on the quality of the survey.

f) Develop layouts / tables presenting data

Establishing the models is needed because depending on the degree of detail can then sample size.

g) Develop sample

The entire structure is determined based sample survey and therefore it is necessary to know the nature and accuracy that base.

h) The completion of research tools

i) Application field instruments

The items that can affect the quality of the survey are: questionnaire, the controller, the physical time, time and day.

j) The quality of information processing

Processing of information include the following:

- quality control documents

- coding responses

- primary processing

- secondary processing

k) The research report

The Research report is the final stage of the investigation and includes generally an introduction to the problem studied, presenting the procedures for collecting and processing information, a summary presentation of results and their interpretation (Novak, 1996).

\section{The unifactorial regression model with qualitative variables}

In quantifying the model described in this paper we are dealing with qualitative nealternative exogenous variables (polihotomice). Sometimes, certain significant factors of an endogenous variables $Y$ are non-quantifiable, with a number of variants nonnumeric. In the area of consumption, these factors relate to socio-professional category, geography, traditions generated by nationality etc.

One way of quantifying such exogenous variables is to encode variants with numbers: $x_{1}=0, x_{2}=1, x_{3}=2, \ldots, x_{k}=k-1$. The econometric model established in this assumption is: $y_{i}=a+b x_{i j}+u_{i}$, (Tudorel and Regis, 2008) where:

$i=\overline{1, n}, j=\overline{0, k-1}, y_{i}=$ the consumption of the family $i$,

$$
x_{i j}=\left\{\begin{array}{c}
0, \text { if the family is part of the socio - professional category } x_{1} \\
1, \text { if the family is part of the socio - professional category } x_{2} \\
k-1, \text { if the family is part of the socio - professional category } x_{k}
\end{array}\right.
$$

In this case, $Y$ endogenous variable environments, subject to the explanatory variable $(x)$, calculated based on the model are:

$$
\begin{gathered}
M\left(\left(y \mid x_{i=0}\right)=a=\overline{y_{1}}\right. \\
M\left(\left(y \mid x_{i=1}\right)=a+b=\overline{y_{2}}\right.
\end{gathered}
$$




$$
\begin{gathered}
M\left(\left(y \mid x_{i=3}\right)=a+2 b=\overline{y_{3}}\right. \\
\ldots \ldots \ldots \ldots \ldots \ldots \ldots \ldots \ldots \ldots \ldots \ldots \ldots \ldots \ldots \\
M\left(\left(y \mid x_{i=k}\right)=a+(k-1) b=\overline{y_{1}}\right.
\end{gathered}
$$

From the above relations that the average consumption of a family constantly increases with the size $b$, as they move from one income group to another, or the difference between the average consumption of two families belonging to the two socioeconomic categories is constant and equal successive with the regression coefficient $b$ : $y_{2}-y_{1}=y_{3}-y_{2}=\ldots=y_{k}-y_{k-1}=b$. Giving equidistant values to nealternative qualitative variants exogenous variables can be used only in a particular case, when the exogenous variable and conditioned media are equidistant.

To avoid this restriction in an econometric model, the nealternative qualitative explanatory variable is inserted through $(k-1)$ binary variables if it shows $k$ arms relative. Thus, if a qualitative explanatory variable has three options $(A, B, C)$ it will be in the form of the econometric model: $y_{i}=a_{0}+a_{1} x_{1 i}+a_{2} x_{2 i}+u$, where: $y_{i}=$ the consumption of the family $i$;

$$
\begin{gathered}
x_{1}=\left\{\begin{array}{r}
1, \quad \text { if the family } i \text { gets the B variant } \\
0, \quad \text { if the family } i \text { doesn't get the } B \text { variant }
\end{array}\right. \\
x_{2}=\left\{\begin{array}{c}
1, \quad \text { if the family } i \text { gets the } C \text { variant } \\
0, \text { if the family } i \text { doesn't get the } C \text { variant }
\end{array}\right.
\end{gathered}
$$

Note that, if: $x_{1}=1 \Rightarrow x_{2}=0 ; \quad x_{2}=1 \Rightarrow x_{1}=0: \quad x_{1}=x_{2}=0 \Rightarrow$ the family $i$ gets the A variant. In this case, the model is equivalent to:

$$
\begin{gathered}
M\left(\left(y \mid x_{0}=1, x_{1}=x_{2}=0\right)=a_{0}=\overline{y_{0}}\right. \\
M\left(\left(y \mid x_{1}=1, x_{1}=0\right)=a_{0}+a_{1}=\overline{y_{1}}\right. \\
M\left(\left(y \mid x_{2}=1, x_{2}=0\right)=a_{0}+a_{2}=\overline{y_{2}}\right.
\end{gathered}
$$

It follows that model parameters are equal: $a_{0}=\overline{y_{0}}, a_{1}=\overline{y_{1}}-\overline{y_{0}}, a=\overline{y_{2}}-$ $\overline{y_{0}}$ where: $\overline{y_{0}}, \overline{y_{1}}, y_{2}$ represents the average level of consumption for families possessing version A, respectively $B$, respectively $C$ (Tudorel and Regis, 2008).

\section{The multifactorial regression model}

On the general form, a multifactorial explanatory model is defined by the following relation: $y=f\left(x_{j}\right)+u$, where: $y=$ endogenous variable, dependent or explained; $x_{j}=$ exogenous variables, independent or explanatory; $j=\overline{1, k}, k=$ the number of exogenous variables; $u=$ residual variable or random or error; $f\left(x_{j}\right)=$ regression function with which will be estimated (approximate) the variable values $y$, determined only by the influence $x_{j}$, considered essential, main, decisive, unless other factors influence of the phenomenon $y$, factors that are considered nonessential, insignificant explain the emergence and evolution in time and space of the phenomenon $y$, them being treated separately using the residual variable $u$. The econometric model should be construed as a formal expression of the method econometric investigation of an economic purpose:

The Reality $(y)=$ The Theory $\left[f\left(x_{j}\right)\right]+$ Random $(u)$

As a general and fundamental rule specifying an econometric model is based on economic theory.

As in the case of the single factor model, the econometric identification consists of choosing a mathematical function to describe the relationship, of the relation between endogenous variable $y$ and its factors of influence, $x_{1}, x_{2}, \ldots, x_{j}, \ldots, x_{k}$. This choice is consistent with the statistical series (series of space or time of the variable $y$ and variables $x_{j}$ ) of these variables, taken from a database or constructed following statistical observations specially organized. Thus, if you have the following information: 


\begin{tabular}{|c|c|c|c|c|}
\hline$x_{11}$ & $x_{21}$ & $\ldots$ & $x_{k 1}$ & $y_{1}$ \\
\hline$x_{12}$ & $x_{22}$ & $\ldots$ & $x_{k 2}$ & $y_{2}$ \\
\hline$x_{13}$ & $x_{23}$ & $\ldots$ & $x_{k 3}$ & $y_{13}$ \\
\hline$\cdot$ & & & & \\
$\cdot$ & & & & \\
. & & & & \\
\hline$x_{1 n}$ & $x_{2 n}$ & $\ldots$ & $x_{k n}$ & $y_{n}$ \\
\hline
\end{tabular}

PICBE | 1093

where: $t=\overline{1, n}, n=$ the number of terms of statistical series; $j=\overline{1, k}, k=$ the number of exogenous variables. Identifying means that, based on experimental data, $y_{t}$ and $x_{j t}$, to find a mathematical function, $Y_{t}=f\left(x_{j t}\right)$, with which estimate the values of the variable $y$ only on the basis of values $x_{j t}$.

Note that, both the model specification stage and the stage of identifying, the solutions accepted:

- $x_{j}$ - the main factors that influence the phenomenon $y$;

- $Y_{t}=f\left(x_{j t}\right)=b_{0}+b_{1} x_{1 t}+b_{2} x_{2 t}+\ldots+b_{k} x_{k t} ;=\overline{1, k}, t=\overline{1, n}$ (Tudorel and Regis, 2008)

- dependency relationship, are nothing but simple hypotheses. The validation or rejection of them will be, in fact, the main objective of the verification stage econometric model.

Application of the M.C.M.M.P. in a multifactor model is based on several assumptions, namely:

I1: Variables $y, x_{1}, \ldots, x_{k}$ are not affected by errors of measurement.

I2: The random variable (residual) $U$ average is null $M\left(u_{1}\right)=M\left(u_{2}\right)=\ldots=M\left(u_{n}\right)=$ 0 , and its dispersion $\sigma_{u}^{2}$ is constant and independent of exogenous variables $X_{j}-$ hypothesis homoscedasticitate.

I3: Residual variable values $U$ are independent, namely the phenomenon of autocorrelation of errors, $\left(u_{1}, u_{n}\right)=0, \forall t, t=\overline{1, n}$.

I4: The law of probability of the residual variable is the normal law of mean zero and standard deviation $\sigma_{u}$.

Outside these assumptions, which are the same in the case of a single factor model, there is a specific hypothesis of the multifactorial model, namely - I5: exogenous variables $X_{j}$ are independent of each other, resulting a system of linearly independent vectors. Otherwise multicolinearity phenomenon occurs involving the impossibility of calculating inverse matrix $\left(X^{\prime} X\right)^{-1}$, and estimation parameters.

\section{Case Study. Implementation of statistical research methods to assess the quality of underground transport in Bucharest}

Starting the year 2012, every year in October-November, The Departement of Marketing, associations, rentals, according to Marketing Plan approved for each year, conducted a poll to assess the quality of service the subway in 16 stations metro considered representative: Piata Unirii 1 și 2, Piata Victoriei 1 și 2, Dristor 2, Nicolae Grigorescu, Universitate, Piața Sudului, Pipera, Eroilor, Gara de Nord 1, Obor, Crângași, Lujerului, Parc Bazilescu and 1 Decembrie 1918. 
Data processing was done by creating a database in Oracle Database or a machete (forms) input data using Oracle Forms Developer, and SQL Developer on instruction type select were the answers for each question.

For the year 2014, the distribution of responses is shown for each question.

Table 1. Q1. On which line do you travel?

\begin{tabular}{|l|l|l|}
\hline $\begin{array}{l}\text { 1. Pantelimon - Gara de Nord - } \\
\text { Dristor 2 }\end{array}$ & 968 & $40.33 \%$ \\
\hline 2. Berceni - Pipera & 437 & $18.22 \%$ \\
\hline 3. Anghel Saligny - Preciziei & 469 & $19.56 \%$ \\
\hline 4. Gara de Nord 2 - Parc Bazilescu & 199 & $8.28 \%$ \\
\hline 5. Have not answered & 327 & $13.61 \%$ \\
\hline TOTAL & 2400 & $100.00 \%$ \\
\hline
\end{tabular}

PICBE | 1094

Table 2. $Q$ 2. Are you satisfied with the subway travel conditions?

\begin{tabular}{|l|l|l|}
\hline 1. YES & $89.44 \%$ & 2147 \\
\hline 2. UNDETERMINED & $0.56 \%$ & 13 \\
\hline 3. NO & $10.00 \%$ & 240 \\
\hline TOTAL & $100.00 \%$ & 2400 \\
\hline
\end{tabular}

Source: Author's own research.

Table 3. $Q$ 3. Have you encountered subway travel deficiencies?

\begin{tabular}{|l|l|}
\hline 1. YES & $31.33 \%$ \\
\hline 2. NO & $63.50 \%$ \\
\hline 3. UNDETERMINED & $5.17 \%$ \\
\hline TOTAL & $100.00 \%$ \\
\hline
\end{tabular}

Source: Author's own research.

Table 4. $Q$ 3.1. Wide time range between trains

\begin{tabular}{|l|l|}
\hline YES & 538 \\
\hline NO & 1812 \\
\hline TOTAL & 2400 \\
\hline
\end{tabular}

Table 5. $Q$ 3.2. Deficiencies concerning the conditions of trains

Source: Author's own research.

\begin{tabular}{|cl|c|}
\hline 1. & Ventilation & $11 \%$ \\
\hline 2. & Features & $8 \%$ \\
\hline 3. & Cleaning & $9 \%$ \\
\hline 4. & Others & $3 \%$ \\
\hline
\end{tabular}

Source: Author's own research.

Table 6. $Q$ 3.3. Deficiencies concerning the conditions of trains

\begin{tabular}{|cl|l|l|}
\hline 1. & $\begin{array}{l}\text { The look of the } \\
\text { stations }\end{array}$ & 129 & $17.77 \%$ \\
\hline 2. & Billing devices & 100 & $13.77 \%$ \\
\hline 3. & $\begin{array}{l}\text { Escalators, } \\
\text { elevators }\end{array}$ & 83 & $11.43 \%$ \\
\hline 4. & Ventilation & 100 & $13.77 \%$ \\
\hline 5. & Cleaning & 272 & $37.47 \%$ \\
\hline 6. & Others & 42 & $5.79 \%$ \\
\hline
\end{tabular}

Source: Author's own research. 
Table 7. $Q$ 4. In what form you asked about the deficiencies?

\begin{tabular}{|rl|l|l|}
\hline 1. & Spoken & 136 & $52.25 \%$ \\
\hline 2. & Written & 53 & $20.22 \%$ \\
\hline 3. & By phone & 72 & $27.53 \%$ \\
\hline & TOTAL & 261 & \\
\hline
\end{tabular}

Source: Author's own research. PICBE | 1095

Table 8. $Q$ 5. How do you assess the reaction METROREX had with respect to the complaints/suggestions?

\begin{tabular}{|rl|l|l|}
\hline 1. & Very good & 17 & $8.21 \%$ \\
\hline 2. & Good & 149 & $71.98 \%$ \\
\hline 3. & Unacceptable & 41 & $19.81 \%$ \\
\hline \multicolumn{2}{r}{ TOTAL } & 207 & $100.00 \%$ \\
\hline
\end{tabular}

Source: Author's own research.

Table 9. $Q$ 6. How do you assess the attitude of staff engaged in activities in Metro?

\begin{tabular}{|l|l|l|l|l|}
\hline & No answer & Unacceptable & Good & Very Good \\
\hline 1.Subway police & $33.17 \%$ & $9.11 \%$ & $34.61 \%$ & $23.11 \%$ \\
\hline 2.Trains guard & $13.27 \%$ & $11 \%$ & $47.72 \%$ & $28 \%$ \\
\hline 3.Station guard & $13.17 \%$ & $11 \%$ & $48 \%$ & $27.61 \%$ \\
\hline 4.Mechanics & $8.17 \%$ & $2.22 \%$ & $48.50 \%$ & $41.11 \%$ \\
\hline 5.Cashiers & $2.61 \%$ & $6.11 \%$ & $54.44 \%$ & $36.83 \%$ \\
\hline
\end{tabular}

Source: Author's own research.

Table 10. $Q$ 7. How do you get informed the traveling public?

\begin{tabular}{|l|l|l|l|l|}
\hline & $\begin{array}{l}\text { Very } \\
\text { Good }\end{array}$ & Good & Unacceptable & $\begin{array}{l}\text { No } \\
\text { answer }\end{array}$ \\
\hline 1. Information signage & $31.33 \%$ & $51.50 \%$ & $8.56 \%$ & $8.61 \%$ \\
\hline 2. Dynamic information & $36.89 \%$ & $43.56 \%$ & $5.67 \%$ & $13.88 \%$ \\
\hline 3. Information on trains & $22.67 \%$ & $62 \%$ & $7.33 \%$ & $8.00 \%$ \\
\hline 4. Info kiosks & $36.06 \%$ & $45.17 \%$ & $3.72 \%$ & $15.05 \%$ \\
\hline
\end{tabular}

Source: Author's own research.

To build the multifactor regression model presented, I used these variables:

Q1N1, Q1N2, Q1N3, Q1N4 - line traveled;

Q3DN - deficiencies;

Q51 - time interval between trains;

Q4 - conditions in trains;

Q53 - conditions in stations;

$\mathrm{Q} 4 \mathrm{~V}, \ldots, \mathrm{Q} 4 \mathrm{~T}$ - notification of deficiencies;

Q5MTX - METROREX S.A. reaction;

Q61, ..., Q65 - staff attitude;

Q91,... , Q94 - informing the traveling public;

Q3N - passenger satisfaction.

Using these variables in EXCEL, using the form I presented, I used the Data Analysis option and got the following results: 
SUMMARY OUTPUT

\begin{tabular}{|c|c|c|c|c|c|c|c|c|}
\hline \multicolumn{9}{|l|}{ ( } \\
\hline \multicolumn{9}{|c|}{ Regression Statistics } \\
\hline Multiple R & 0.313690076 & & & & & & & \\
\hline R Square & 0.098401464 & & & & & & & \\
\hline Adjusted R Square & 0.092373224 & & & & & & & \\
\hline Standard Error & 0.308674503 & & & & & & & \\
\hline Observations & 2410 & & & & & & & \\
\hline \multicolumn{9}{|l|}{ ANOVA } \\
\hline & $d f$ & $S S$ & $M S$ & $F$ & Significance $F$ & & & \\
\hline Regression & 16 & 24.88470942 & 1.555294339 & 16.32341706 & $1.00257 \mathrm{E}-43$ & & & \\
\hline Residual & 2393 & 228.0049171 & 0.095279949 & & & & & \\
\hline \multirow[t]{2}{*}{ Total } & 2409 & 252.8896266 & & & & & & \\
\hline & Coefficients & Standard Error & t Stat & $P$-value & Lower 95\% & Upper 95\% & Lower $95.0 \%$ & Upper $95.0 \%$ \\
\hline Intercept & 1.791399203 & 0.036249477 & 49.4186223 & 0 & 1.720315581 & 1.862482825 & 1.720315581 & 1.862482825 \\
\hline Q1N1 & 0.012454862 & 0.007290021 & 1.708480954 & 0.087676818 & -0.001840547 & 0.02675027 & -0.001840547 & 0.02675027 \\
\hline Q1N2 & -0.013520661 & 0.007249699 & -1.864996279 & 0.062304239 & -0.027736999 & 0.000695678 & -0.027736999 & 0.000695678 \\
\hline Q1N3 & 0.003189884 & 0.007814535 & 0.408198836 & 0.683164223 & -0.012134074 & 0.018513842 & -0.012134074 & 0.018513842 \\
\hline Q1N4 & -0.00088876 & 0.009171836 & -0.096901037 & 0.9228131 & -0.018874326 & 0.017096805 & -0.018874326 & 0.017096805 \\
\hline Q3DN & -0.020870036 & 0.013067209 & -1.597130305 & 0.110368696 & -0.046494256 & 0.004754184 & -0.046494256 & 0.004754184 \\
\hline Q51 & -0.059366227 & 0.008332029 & -7.125062263 & $1.37088 \mathrm{E}-12$ & -0.075704968 & -0.043027486 & -0.075704968 & -0.043027486 \\
\hline Q4 & -0.136252871 & 0.030127936 & -4.522476184 & 6.41023E-06 & -0.195332422 & -0.077173321 & -0.195332422 & -0.077173321 \\
\hline Q53 & -0.03917946 & 0.030181352 & -1.298134672 & 0.19436616 & -0.098363758 & 0.020004838 & -0.098363758 & 0.020004838 \\
\hline Q5MTX & 0.002435057 & 0.008212962 & 0.296489468 & 0.766882038 & -0.013670199 & 0.018540312 & -0.013670199 & 0.018540312 \\
\hline Q61 & 0.042913371 & 0.012719333 & 3.373869702 & 0.000753003 & 0.017971322 & 0.067855421 & 0.017971322 & 0.067855421 \\
\hline Q62 & 0.002638336 & 0.01177406 & 0.224080378 & 0.822713889 & -0.020450076 & 0.025726748 & -0.020450076 & 0.025726748 \\
\hline Q63 & 0.001804448 & 0.00803581 & 0.224550896 & 0.822347839 & -0.01395342 & 0.017562317 & -0.01395342 & 0.017562317 \\
\hline Q64 & -0.001023241 & 0.013213937 & -0.077436493 & 0.938282785 & -0.026935188 & 0.024888706 & -0.026935188 & 0.024888706 \\
\hline Q65 & 0.014077079 & 0.012465648 & 1.129269782 & 0.258897232 & -0.010367505 & 0.038521664 & -0.010367505 & 0.038521664 \\
\hline Q91 & 0.010415657 & 0.012052809 & 0.864168463 & 0.387581965 & -0.013219368 & 0.034050682 & -0.013219368 & 0.034050682 \\
\hline Q92 & 0.010755461 & 0.01095959 & 0.98137437 & 0.326507366 & -0.010735811 & 0.032246734 & -0.010735811 & 0.032246734 \\
\hline
\end{tabular}

Figure 1. Summary output

Source: Author's own research.

Using these variables in IBM SPSS, using the form I presented, I used the Data Analysis option and got the following results:

Table 11. Variables Entered/Removed ${ }^{a}$

\begin{tabular}{|l|l|l|l|}
\hline Model & Variables Entered & \multicolumn{1}{|l|}{$\begin{array}{l}\text { Variables } \\
\text { Removed }\end{array}$} & Method \\
\hline \multirow{4}{*}{1} & Q4T, Q4S, Q4, Q61, & & \\
& Q1N3, Q1N4, & & \\
& Q3DN, Q1N2, Q93, & & Enter \\
& Q4V, Q65, Q94, & & \\
& Q1N1, Q51, Q63, & & \\
& Q91, Q62, Q92, & & \\
& Q53, Q64, Q5MTX & & \\
\hline
\end{tabular}

a. Dependent Variable: Q3N

b. All requested variables entered.

Table 12. Model Summary and ANOVA

\begin{tabular}{|l|r|r|r|r|}
\hline Model & \multicolumn{1}{|c|}{$\mathrm{R}$} & R Square & Adjusted R Square & $\begin{array}{c}\text { Std. Error of the } \\
\text { Estimate }\end{array}$ \\
\hline 1 & $.328^{\mathrm{a}}$ & .108 & .100 & .307 \\
\hline
\end{tabular}

a. Predictors: (Constant), Q4T, Q4S, Q4, Q61, Q1N3, Q1N4, Q3DN, Q1N2, Q93, Q4V, Q65, Q94, Q1N1, Q51, Q63, Q91, Q62, Q92, Q53, Q64, Q5MTX

ANOVA $^{\mathrm{a}}$

\begin{tabular}{|c|c|c|c|c|c|c|}
\hline & Model & $\begin{array}{c}\text { Sum of } \\
\text { Squares }\end{array}$ & df & $\begin{array}{c}\text { Mean } \\
\text { Square }\end{array}$ & $\mathrm{F}$ & Sig. \\
\hline \multirow{3}{*}{1} & Regression & 27.248 & 21 & \multirow{3}{*}{$\begin{array}{r}1.298 \\
.094\end{array}$} & \multirow[t]{3}{*}{13.732} & \multirow[t]{3}{*}{$.000^{\mathrm{b}}$} \\
\hline & Residual & 225.642 & 2388 & & & \\
\hline & Total & 252.890 & 2409 & & & \\
\hline
\end{tabular}

a. Dependent Variable: Q3N

DOI: 10.1515/picbe-2017-0112,pp. 1088-1100, ISSN 2558-9652| Proceedings of the $11^{\text {th }}$ International Conference on Business Excellence 
b. Predictors: (Constant), Q4T, Q4S, Q4, Q61, Q1N3, Q1N4, Q3DN, Q1N2, Q93,

Q4V, Q65, Q94, Q1N1, Q51, Q63, Q91, Q62, Q92, Q53, Q64, Q5MTX

Table 13. Coefficients ${ }^{a}$

Source: Author's own research.

\begin{tabular}{|l|r|r|r|r|r|}
\hline \multicolumn{1}{|c|}{ Model } & \multicolumn{2}{|c|}{ Unstandardized Coefficients } & \multicolumn{1}{c|}{$\begin{array}{c}\text { Standardized } \\
\text { Coefficients }\end{array}$} & \multicolumn{1}{l|}{ Sig. } \\
\cline { 2 - 4 } & B & Std. Error & Beta & \\
\hline (Constant) & 1.796 & .036 & & 49.454 & .000 \\
Q1N1 & .010 & .007 & .030 & 1.353 & .176 \\
Q1N2 & -.010 & .007 & -.031 & -1.435 & .152 \\
Q1N3 & .004 & .008 & .010 & .449 & .653 \\
Q1N4 & .002 & .009 & .004 & .176 & .861 \\
Q3DN & -.017 & .013 & -.030 & -1.331 & .183 \\
Q51 & -.056 & .008 & -.152 & -6.678 & .000 \\
Q4 & -.134 & .030 & -135 & -4.476 & .000 \\
Q53 & -.044 & .030 & -.045 & -1.467 & .143 \\
Q5MTX & .039 & .013 & .099 & 3.113 & .002 \\
Q61 & .039 & .013 & .076 & 3.091 & .002 \\
Q62 & .005 & .012 & .011 & .399 & .690 \\
Q63 & -.001 & .008 & -.003 & -.134 & .893 \\
Q64 & -.001 & .013 & -.001 & -.045 & .964 \\
Q65 & .013 & .013 & .032 & 1.044 & .297 \\
Q91 & .005 & .012 & .010 & .406 & .685 \\
Q92 & .004 & .012 & .009 & .317 & .751 \\
Q93 & -.001 & .008 & -.003 & -.127 & .899 \\
Q94 & .015 & .010 & .039 & 1.528 & .127 \\
Q4V & -.044 & .013 & -.105 & -3.466 & .001 \\
Q4S & -.108 & .026 & -.087 & -4.149 & .000 \\
Q4T & .002 & .022 & .002 & .082 & .935 \\
\hline
\end{tabular}

PICBE | 1097

Source: Author's own research.

\section{Online Surveys. Implementing an online survey METROREX S.A.}

Online surveys based on a Web site consists of publishing on its website the company or a host site a banner or hyperlink to the page where the questionnaire is to be completed by the respondents selected based on predetermined criteria.

The online environment offers organizations the ability to communicate and interact online with customers by individualizing and personalizing their needs and requirements, following their meeting at a higher level by establishing partnerships in a global market interactive virtual world.

Conducting surveys online has an advantage by the existence of web-based platforms that enable the design, collection and interpretation of research results simply in a very short time, in real time, at very low cost with completing and processing errors insignificant. Results are interactive presented, in graphical or tabular form and can be viewed in real time as the questionnaires is completed by the target group established prior and invited to fill in the questionnaire.

For security and truthfulness of the completing the questionnaire, one time by each participant, online platforms verifies the authenticity of the information respondent host computer ID and cookies. Cookies are small text files managed by the application software stored on computer respondent. The application collects addresses of these websites (URLs), which are visited by this user and records the visit in them, 
and the names of active processes, without collecting the contents of e-mails, chats and passwords. The application works so to be complete invisible to the user. The only indication that the application works is displaying a login window with username request to determine the person who will use the browser (Stoica, 2014).

\section{Conclusions}

PICBE $\mid 1098$

The ratio of determination $R^{2}$ shows the proportion of variation in the dependent variable explained by the regression model and is used to assess the quality adjustment (model selection). $R^{2}$ has values between 0 and 1 . If $R^{2}$ equals 0 or is very low, in our case $R^{2}=0,108$, then the regression model chosen does not explain the link between variables.

It can be seen that $F_{c}=13,732$ and Sig. $=0<0.05$ which means that the independent variables does not explain the variation in the dependent variable $\mathrm{Q} 3 \mathrm{~N}$ passenger satisfaction, so the linear relationship between the variables considered is not about significant.

Coefficients table presents non-standardized coefficients of the regression model estimates, standard errors of their standardized regression coefficients with corresponding standard errors and test statistics values $t$ and values Sig.. Standardized regression coefficients are used when a regression model has several independent variables expressed in different units of measure in order to facilitate their comparison.

Testing regression model parameters is performed using the $t$ test to find out how likely each parameter to be null. For the example which I presented, the value Sig. is significant only when it is less than 0.05: Q51 - time interval between trains, Q4 conditions in trains, Q5MTX - METROREX S.A. reaction, Q61 - staff attitude Cashiers, access control, Q4V, Q4S - verbal and written notification of deficiencies.

Those who answered NO (unsatisfied) are traveling from the stations: Piața Victoriei 2(17,33\%), Obor(14,67\%) și Gara de Nord 1(13,33\%). Considering that subjects who answered YES (satisfied) signaled deficiencies in stations and trains, subway service is appreciated by most passengers (90,34\%).

Deficiencies were noted for 749 passengers (31.2\%) of the 2400 questionnaire and thus are centralized:

3.1. Wide time range between trains

3.2. Deficiencies concerning the conditions of trains

3.3. Deficiencies concerning the conditions of stations $\quad 37,27 \%$

Those 749 travelers have ticked one or more of the questions below and also ticked more of an issue or question below.

Deficiencies were noted in 261 questionnaires (10.9\%) of the 2,400 questionnaires centralized and are as follows:
4.1. Spoken
$6,21 \%$
4.2. Written
$2,08 \%$
4.3. By phone
$2,58 \%$

The main directions for improving the quality of underground transport in Bucharest targeting issues such as reducing time interval between trains, more cleanliness, a better information to passengers, signage, flyers, the construction of toilets in all metro stations, improve ventilation in trains and stations, modernisation of stations. The study also offers a measure of service quality and customer satisfaction for public transport by the subway and has an impact on future investment projects to improve better underground transportation. 


\section{References}

Isaic-Maniu, A., Mitrut, C., Voineagu, V. (1999). Statistica pentru managementul afacerilor, Editura Economică, București.

Novak, A. (1996). Sondarea opiniei publice, Editura Studențeascã, București,

Porojan, D. (2006). Statistica și teoria sondajului, Casa de editurã şi presã ŞANSA S.R.L, București.

Rotariu, T., and Iluț, P. (2006). Ancheta sociologică şi sondajul de opinie, editia a II-a, Ed.Polirom, Iaşi,

Stoica, I. (2014). Ghid practice pentru realizarea sondajelor online, Editura Uranus, București.

Tudorel, A., Regis, B. (2008). Econometrie, Editura Economică, București.

Zamfir, C., Vlăsceanu, L. (1993). Dicţionar de sociologie, Ed. Babel, București.

\section{Appendix}

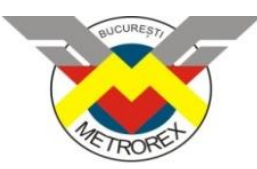

\section{METROREX S.A.}
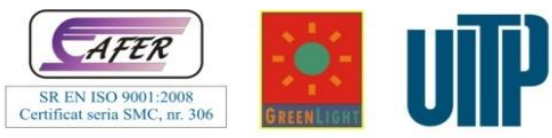

www.metrorex.ro

QUESTIONNAIRE Nr. 01 / 2014

The questionnaire does not contain personal data and should not be signed!

Thank you in advance for your opinion and time for answers

1. Which metro line do you predominantly operate?

line 1: Pantelimon - Gara de Nord - Dristor 2

line 2: Berceni - Pipera

line 3: Anghel Saligny- Preciziei

line 4: Gara de Nord2- Parc Bazilescu

2. Are you pleased with the conditions of the metro travel? 


\subsection{Deficiencies in station conditions}

3.3.1. The layout of the

stations

3.3.2. Billing devices

3.3.3. Escalators, elevators

3.3.4. Ventilation

3.3.5. Cleaning

3.3.6. Others

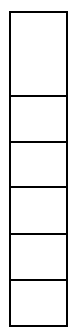

PICBE | 1100

4. In what format did you notify them about the deficiencies?

\section{Spoken \\ Written \\ By phone}

5. How do you rate METROREX's reaction to complaints / suggestions made?

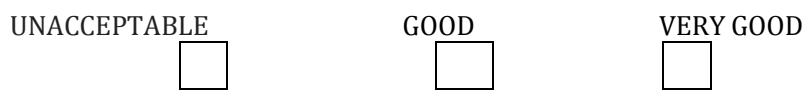

6. How do you appreciate the attitude of the staff interacting with the traveling public?

Cashiers, access control

Mechanics

Staff guard in stations

Staff guard in trains

Staff underground police

UNACCEPTABLE

7. How do you rate travelling public information?
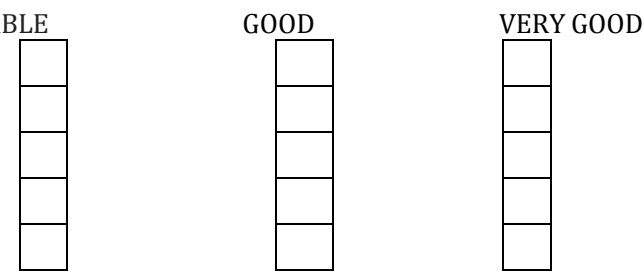

Information / orientation signaling Dynamic display monitors in stations Signaling and information in trains Info kiosks UNACCEPTABLE
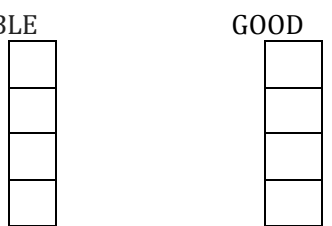

VERY GOOD

8. If you have any other comments / suggestions regarding the metro transport service, please use the space below.

\begin{tabular}{ll}
\hline Asking person & Hour \\
Station & Line \\
\hline
\end{tabular}

THE TRAVELER'S PHONE NUMBR 021.9264, e -mail: contact@metrorex.ro 